\title{
The Messiness of Ethics in Education
}

\author{
Johanna Cliffe ${ }^{1}$ (D) $\cdot$ Carla Solvason $^{2}$ (D)
}

Accepted: 19 February 2021 / Published online: 6 March 2021

(c) The Author(s) 2021

\begin{abstract}
This article considers the multifaceted concept of ethics and how, despite being a familiar notion within education, it is still much contested within literature and professional practice. Drawing on postmodern, feminist and political literature, the authors explore (re)conceptualisations of ethics and ethicality in relation to ethical identity, professionalism and practice. Applying philosophical and metaphorical tools, such as the rhizome and nomad (Deleuze and Guattari, 1987), the authors suggest there is the potential to accommodate the multiple and often divergent facets of ethics, thereby engaging with different ethical possibilities. It is argued that the propensity for reducing ethics to merely procedural protocols and guidelines marginalises the richness of ethics and, all too frequently, leaves practitioners ill-equipped to navigate the reality of day-to-day ethics.

The article is positioned within the field of early years (EY) practice and training EY practitioners. This reflects the authors' own specialism but also celebrates the propensity of the EY practitioner to reflect upon, question and challenge their own practice and ethical identities. This does not reduce the applicability of the subject matter which is relevant to educators of children of any age. The term 'practitioner' is used throughout to refer to any adult working with children in an educative role, this includes, but is not limited to nursery nurses, teachers or teaching assistants.
\end{abstract}

Keywords Ethics $\cdot$ Ethicality $\cdot$ Rhizomes $\cdot$ Nomad $\cdot$ Early childhood education

\section{Ethical Beginnings...an Introduction...}

"Ethics is a species activity that includes everything we do to maintain, continue and repair our world so we can live in it as well as possible"

Fisher and Tronto (1990, 40).

The purpose of this paper is to widen the academic debate surrounding the nebulous field of ethics. As tutors within further education with the responsibility of training our future educators we have been unsatisfied with the more typical conversations around

Johanna Cliffe

johanna.cliffe@learninginstitute.co.uk

1 The Learning Institute, Victoria, Roche, UK

2 School of Education, University of Worcester, Worcester, UK 
ethics in early years education and have decided to explore (re)conceptualisations of ethics and ethicality in order to engage differently. We have felt the propensity for reducing ethics to merely procedural protocols and guidelines marginalises the richness of ethics and, all too frequently, leaves practitioners ill-equipped to navigate the reality of lived ethics in everyday practice with children, families and colleagues. As we will discuss later in the paper, we have issue with not only with the tenor of current ethical conversations within the field, but additionally with the marginalisation of ethics within teacher training (Malone, 2020): an unsound situation which increases the potential for moral distress within the workforce (Ribers, 2018). Therefore, we will draw on Deleuzo-Guattarian (1987) philosophical tools, such as the rhizome and nomad, to engage with the potential for accommodating the multiple and often divergent facets of ethics, in attempt to bring fresh insight and, thereby, openup to different ethical possibilities. We do not seek to offer a unified vision of ethics, for as this discussion will demonstrate, ethics is a complex concept and unification, alongside any claims to 'truth', would contravene the very positionality of the debate.

Ethics is a familiar term that is used frequently within education, particularly with regard to educational research and yet, as Gallagher $(2009,11)$ maintains, it remains hard to define as a concept and is widely contested. Ethical definitions often weave between macro and micro terrains depending on the focus and importance it is ascribed. The introductory quote from Fisher and Tronto (1990) infers that ethics is an innately human condition that underpins what it means to be human, living a human life. This is further supported by postmodern philosophers such as Bauman (1995, 10), who suggest ethics is and should be the concern of everyone but purports "ethics is more than a mere description of what people do; more even than a description of what they believe they ought to be doing to be decent, just and good" it is a fundamental code that "sets apart good and evil" (Ibid). Therefore, two questions emerge; how best to ensure the practitioners that we have a hand in training fully understand and are prepared for ethical responsibility where the most vulnerable in our society are concerned? And how should something so fundamental to human development as the understanding of 'right and wrong' be tackled in a child's early education?

Feminist and political theorists such as Tronto (2013) and Noddings (2015) promote the notion of an ethics of care where ethics is morally situated and contextualised through responsibilities and relationships. Whereas, others draw on the work of Levinas (1989 cited in Dahlberg \& Moss, 2005, 76-81) to discuss the ethics of encounter and a respect and authentic acknowledgment of the Other. However, within Early Years Education (EYE) and other educational institutions and professions, the very nature of being an educator can be considered to be bound by implicit ethical and moral duties, responsibilities and principles. This not only encompasses identity (both professional and personal) but also behaviour and conduct (both professional and personal), and professional practice (Early Education, 2011; National College for Teaching and Leadership (NCTL) 2013; Whitehead and Aviles, 2018). Furthermore, Dahlberg and Moss (2005) and Moss (2019) contend that EYE is by its very nature both political and ethical and, whilst this may make many early years (EY) practitioners uncomfortable, to imagine otherwise risks reducing EYE to merely technical, normative and dominant practices and discourses.

Bazzul $(2018,474)$ observes that "there is literally an infinite number of ways of living and being ethical". It is within this nebulous context that this article hopes to offer further thoughts to add to the academic debate surrounding the field of ethics and the influence different visions of ethics may have on practitioners. The discussion is situated within the field of EYE due to the authors' own experience, but it could easily be transposed into any phase of education. It does not seek to provide answers or correct universal truths 
pertaining to ethics. However, employing Deleuzo-Guattarian (1987) theory, through metaphors such as the rhizome it offers a way to consider and accommodate the multiple, and often divergent, facets of ethics and to engage with different ethical possibilities. In undertaking this it is hoped that students and newly qualified practitioners can be better prepared for the messiness of ethics within EYE. Furthermore, it offers suggestions to tutors working with EYE and other educational students of ways to better guide them through this ethical swamp (Punch, 1994).

\section{Rhizomes and Ethical Positionality}

Within this section a brief explanation of the metaphorical concept of rhizome is offered in an attempt to contemplate ethics differently. This will provide a philosophical framework in which diverse ethical concepts can coexist and the richer fuller picture of ethics can be more adequately accommodated. This exploration provides the ethical positionality from which the debates running through this paper have been considered.

Deleuze and Guattari's (1987) metaphorical concept of the rhizome offers a versatile way of exploring and engaging with ethics. They maintain the rhizome is a multiplicitous structure with connections, or growth that travels in any and all directions. Rhizomes never retrace their pathways, more they constantly (re)evolve via multiple entries and exits to regenerate and (de/re)territorialise new trajectories. As a philosophical and conceptual paradigm the metaphorical rhizome offers opportunities for practitioners, indeed all educators, to occupy more flexible conceptual spaces. A rhizomatic philosophy demands that practitioners stop, and pay attention to the multiplicity and complexity around them in order to see things differently; to uncover layers of meaning and connection that may not have been predicted or may not have been seen before. By challenging practitioners to ask critically reflective questions such as what else exists here? How does it work? 'and... and... and' (Deleuze and Guattari, 1987), instead of only trying to categorise as the same, the opportunity to (re)imagine and (re)conceptualise thinking, practice and ethical relational encounters is embraced: essentially practitioners are given the freedom to explore within the rhizome.

Uzelman (2005) uses the concept of bamboo to effectively expand on the DeleuzoGuattarian metaphor. He states "while on the surface each shoot appears to be an individual, related but separate from its neighbours, underground all are connected through a complex network of root-like stems and filaments called a rhizome" (ibid, 17). Although Uzelman applies this metaphor to the notion of activism, it could be argued it offers much in relation to ethics. An individual's (or in this instance practitioner's or educator's) worldview; their values, beliefs and ethical and moral stances, are like the horizontal growth part of the bamboo. They lay under the surface gathering the conceptual nourishment and nutrients needed for dynamic vertical growth, much like the "unseen grassroots" (Uzelman, 2005 , 17). 'Roots' of an individual's ethical values could be seen to act and affect any and all relational encounters, these could be viewed as the visible, vertical growth. Thereby, ethics and ethical values underpin practitioner identity (professional and personal), behaviours and conduct, professional practice and other states of being. Ethics becomes the horizontal and vertical framework that encourages practitioners to (de/re)territorialize old terrains, belief systems, discursive and dominant discourses and chart and honour new and unpredictable ways of being and thinking. In this way the Deleuzo-Guattarian (1987) metaphor lends itself to accommodate the philosophical perspective of ethics (grass roots 
horizontal connections), the more contextualised and situated perspectives (horizontal or vertical growth), and the more universal ethics applied within codes and regulations (vertical growth). The concept of the rhizome allows us to accommodate a vision where multiple perspectives can be acknowledged and function simultaneously, where unpredictable, remarkable or new lines of growth can be accommodated and where new territories, with multiple entries and exits, can be (re)conceived.

As previously stated Bazzul $(2018$, 474) claims that "ethical subjectivity, how one comes to understand themselves as an ethical being, is limitless because there are literally an infinite number of ways of living and being ethical". Bazzul (ibid) argues that when considering ethics it is a question of considering the coexistence of ethical perspectives, stances and facets rather than unification. Thus a fuller and richer picture of ethics can be (re)conceptualised by resisting normative and hegemonic amalgamations; by embracing a multiplicitous, constantly (re)evolving assemblage of ethics. Within this, space is created for practitioner and children's own values and belief systems, based upon their own experiences and understandings, to be developed.

\title{
Problematising Ethical Definitions and the Complexity of the Debate
}

\author{
"Ethics is the conscious practice of freedom...freedom is the ontological condition \\ of ethics. But ethics is considered the form that freedom takes when it is informed by \\ reflection".
}

Foucault (1984, 284).

In order to engage with wider ethical issues and address the importance of ethicality within early years practice, there must first be an understanding of the problematic nature of ethical definitions. An exploration of just was it meant by, or encompassed within the overarching title of 'ethics' must be explored in order to fully contextualise the complex nature of ethics and ethical debates.

Ethical definitions include many differing perspectives and it could be argued that each one will influence how practitioners approach ethics and the importance that they accord it within their practice. The works of Tronto (2013) and Noddings (2015) suggest that ethics is like a mantle of responsibility, in order for practitioners to be prepared to assume this mantle they need to know why ethics is so fundamental and important to every day provision and professionalism; yet ethics is marginalised within teacher training (Aubrey, 2000; Malone, 2020). Although it is beyond the scope of this article to provide exhaustive investigation of fundamental ethics perspectives, some considerations which are relevant to those teaching in early years are discussed below.

Bauman $(1995,10)$, Banks and Gallagher $(2008,16)$ and Gallagher's $(2009,11)$ suggestions initially offer the rather simplistic version of the dualism between binary arguments rooted in right and wrong and, in Bauman's case, good and evil. Ostensibly, Banks and Gallagher $(2008,16)$ claim "ethics can be the values that people hold and follow" or "a singular term referring to the study of norms and values". Furthermore, Dahlberg and Moss (2005, 66) describe ethics as the "categorical distinction between right and wrong" which is then universally applied to promote normative, technicist approaches that govern "how we should think and act" (ibid). This binary and rather constrained view reflects the approach that we most commonly see in the EY classroom or setting; a rather Cartesian approach to ethics founded on common and good-sense that seeks to ascribe a universal consensus relating to values, beliefs, symbolic meaning and binary codification (Shockey, 
2010). This dichotomous and binary argument initially appears to offer a universal starting point which seeks agreement on the basic tenet of good/bad, right/wrong; one being preferable to the other. However, even supposing that when viewed at either end of the spectrum there could be commonality between what is considered good/bad and/or right/wrong by diverse individuals, the numerous shades of grey in between are problematic. Freire (1994) suggests that those who get to decide on what is considered good/bad, right/wrong and within what context or situational encounter, can perpetuate issues of silence and privilege. This, in itself is an innately unethical prospect that has implications for social justice and equitable discourses. Additionally, Tronto $(2013,34)$ argues that the political community within each culture will determine what values, beliefs, moral standpoints and ethical principles find value and voice within the various professional and social communities. Not all voices are heard, not all individual's views within the community of the EY setting will be respected. Binary good/bad, right/wrong decisions, then, may not be as innocent, valuefree or universal as they first appear.

Early Education $(2011,5)$ extends this binary argument further, claiming that when we consider ethics in relation to young children it "involves critical reflection on morality and the ability to make choices between values and the examination of the moral dimensions of relationships". Therefore, ethical decisions are individualised matters of choice. In contrast, Whitehead and Aviles' $(2018,5)$ view that "ethics is a specific set of principles, values, and beliefs that govern the behaviour of individuals or groups"; proposing that a code of ethics is something that exist outside of the individual, universal rules to be abided by. Gallagher $(2009,11)$ observes that there are fundamental distinctions between ethical philosophy and ethical mechanisms, yet they are often conflated and broadly considered 'ethics'. Furthermore, Erickson et al. $(2008,15)$ argue there is a tendency to reduce ethics to "a quasi-legal endeavour" which potentially supports policies and protocols but could be argued to sidestep wider issues of morality and social justice. Foucalt $(1983,1984)$, Niesche and Haase (2012) and Bazzul (2018) imply ethics should encompass more than the governance of behaviour, it should consider how the impacts of particular ethical positions affect relationships. For a practitioner this could be reflecting on their own professionalism and their own interactions or, encouraging children to consider their relationship with self, with others or the wider world and environment. Similarly, Moss (2019) draws on the understandings of postmodern ethics, ethics of care and ethics of encounter, to suggest that practitioners should embrace ethics as an active practice that encompasses and acknowledges their individual responsibilities and relationships, over unification and legislative codes and regulatory guidelines. Examples of this in practice have been when approaches such as 'transformative justice' (Kose, 2011) have been introduced into schools, enabling children to consider how their actions impact upon others, rather than adults imposing rules and regulation in a more behaviouristic manner.

Dahlberg and Moss $(2005,67)$ argue that a unified vision of ethics underpins policy and practice within EYE, however, to continue to attempt to pigeonhole ethics assumes the ontological position that there is a right definition and application of ethics, a stance that may not be coherent in every context. In seeking a one-size-fits all approach to ethics it could be that we are seeking ways to make Other function as the Same, passing it through the "knowers prefabricated system of understanding, concepts and categories" (Dahlberg and Moss, 2005, 77). Often this is done subconsciously; we take Other and assimilate it through our own internal systems, turning it into the something we are more comfortable with or something that makes greater sense to us. Dahlberg and Moss $(2005,77)$ suggest that this not only supports the reduction of feelings of uncomfortableness, but can be a way of "affirming self and what it means to be an independent autonomous being". It is easy 
to see why this is done, it is important to consider the impact that this has on the eclectic thinking and 'one hundred languages' (Edwards et al., 2011) of children.

Within conformity, unity and Sameness there is more than a measure of comfort, stability and security. It could be that this provides a powerful and understandable inducement to seek unification of ethics and conformity within ethical codes and guidelines. Not only does this make ethics more predictable, it also absolves us from the responsibility of making decisions when dealing with day-to-day ethical dilemmas, and uncertainties (Malone, 2020). Essentially, as Dahlberg and Moss $(2005,68)$ contend "what is called for from the individual, for example the preschool practitioner, is conformity to the prescriptions for the code and the terms of the contract through the application of the correct technology. Responsibility is exchanged for legislation, the need to choose for rule-following, ambivalence for certainty". Yet Bauman (1995) reminds us that the human condition tends to be far more chaotic, muddled and ambiguous, with no clear-cut black/white positions. This is particularly relevant in EYE, where there are many inherent moral and ethical dilemmas to navigate due to the complex and collaborative nature of the field (Malone, 2020). Daily interactions not only with children and immediate colleagues, but with families and a wide range of professionals exponentially increases the likelihood of discord and decisions about the course of action that is right.

Tronto (2013) and Noddings (2015) claim that ethics requires an individual, or in this instance a practitioner, EY or otherwise, to assume the mantle of responsibility for accepting and caring for the Other within their interactions. This assumes that inherent within ethics is a strong relational facet that reflects the inter-dependence of encounters and interactions. By accepting Other there is the potential to 'repersonalise' ethics, thereby opening the possibility of new and different on every level (Dahlberg and Moss, 2005, 70) and from every perspective. This, in itself, is an ethical act, a conscious choice to acknowledge and respect Other in a way that not only aligns with care ethics but also that of ethical encounters (Levinas 1989 cited in Dahlberg and Moss, 2005, 76-81). Approaching ethics in this way promotes a more active and agentic ethical practice, a way of living ethics, as opposed to merely accepting and perpetuating legislation. As Bauman $(1995,7)$ states "with the smokescreen of centralised legislation dispersed and the power-of-attorney returned to the signatory, the choice is blatantly left to the moral person's own devices. With choice comes responsibility. And if choice is inevitable, responsibility is unavoidable”. Moss $(2019,59)$ claims that EY practitioners, indeed all educators, when engaging with ethical living must "grapple with context, complexity, ambiguity and uncertainty to decide what it means to relate to the Other in a caring way". Only when practitioners do this can they acknowledge what ethics could be rather than what it is reduced to be. Only then can they truly repersonalise and (de/re)conceptualise ethics to challenge and problematise technical, normative and dominant practices and discourses that may function in inequitable and innately unethical ways.

As suggested within the quote that opened this section, Foucault (1984) proposes that ethics requires individuals to consciously engage with and reflect on freedom. To be precise, ethics becomes an act of freedom when individuals are given opportunities to form their own ethical judgements drawn from reflections on their own ethicality. It is in how each individual presides over their own morality and ethical conduct which becomes an act of freedom, rather than just conformity to ethical regulations and procedural guidelines without reflexive thought. It was from this stance that authentic ethical meaning and ethical living could be contended, furthermore, enacting freedom is an act inherently political and imbued with power. Building on this Bazzul $(2018,472)$ argues that in order to understand and acknowledge authentic ethical living there first has to be an acceptance of "the limits 
and extents of freedom". It could be argued that freedom for an EY practitioner is about understanding and enacting choice within the confines of the power relations and differing social contexts inherent in EYE, particularly in relation to child-practitioner and parentpractitioner dyad and the dynamic between colleagues. Therefore, ethical issues for each and every EY practitioner not only incorporates universal definitions of ethics and conformity with technical practices, but also the limits and extents of freedoms, the acceptance of Other and the willingness to shoulder responsibilities and relationships within uncertainty and ambiguity. Ribers $(2018,902)$ suggests that this may result in "moral distress" for practitioners, particularly as ethics is not considered in real depth within teacher training (Malone, 2020). Practitioners are simply not prepared for these complexities.

The points raised above suggest that practitioners may need to maintain an awareness of the infinite number of ways of living and being ethical (Bazzul, 2018, 474) and it is here that Deleuze and Guattari's (1987) metaphor of the rhizome can offer a conceptual way forward. To return to Uzelman's (2005) rhizomatic description of the bamboo; practitioners can find their own limits and extensions of freedoms encompassed within their horizontal terrain, their "grassroots". If practitioners consciously reflect on their own professional and personal ethical positions, opportunities for understanding more fully what nourishes their ethical interactions will emerge, allowing them, upon reflection, to chart new ways of being and thinking (horizontal growth). The Rhizome offers practitioners the opportunity to resist binary definitions and becoming mired in fixed positions, and instead allow for multiplicity; recognising that there are infinite ethical ways to exist and flourish simultaneously (Deleuze and Guattari, 1987). In doing so they open opportunities that acknowledge and respect the individual ways of knowing and being ethical that can flourish in their classrooms and settings.

\section{Ethical Identity and the Ethical Practitioner, Exploring Ethical Expectations Within EYE}

"Fish don't know they are swimming in the water, until they are a fish out of water. It is when culture shifts that we recognise the ocean in which we have been drenched"

Gilligan (2011, 15-16).

Despite education as a whole being considered an innately ethical profession, the potential ethical expectations of working in EYE and the preparation given to newly qualifying practitioners is often minimal. Furthermore, the expectations for ethical compliance within the profession do not necessarily match the complex reality of working within the sector, nor does the reality always match practitioner idealism regarding individual professional and ethical identity. Therefore, it is reasonable to explore how professional tensions can impact on not only how ethics is viewed as a concept, but the importance it is accorded within practice.

If, as we suggest, the rhizome offers a reasonable way forward from which to envision ethics, then the rationale for an exploration of ethical identity and professional ethics becomes clear (Deleuze and Guattri, 1987; Uzelman, 2005). Whatever ontological positionality practitioners have regarding ethics, the way they reconcile their own ethical identity, personally and professionally, will inform, or provide points of rhizomatic intensity that will impact on the way that they view and engage with ethics. However, there are tensions within this process as identified by Taggart (2011), Barron (2016), Ribers (2018) and Malone (2020), when a practitioner's ethical positionality 
and compliance with hegemonic legislative codes and regulations do not align. The dilemma, as Ribers (2018 p.897) observes, is how EY practitioners reconcile and develop an ethical consciousness within EYE in relation to the subjective relational context within which they work.

Despite there being an implicit understanding that educators are seen as innately moral and ethical ( and certainly this would be the espoused belief of many educators), Aubrey et al. (2000), Ribers (2018) and Malone (2020) highlight that ethics and ethical conduct are not prioritised within teacher training and practice preparation. Although these articles consider the dilemma from the cultural perspective of Denmark and the US, the situation is no different within the UK, as Taggart (2011) and Barron (2016) discuss. In fact the early years teaching standards produced by the NCTL (2013) do not mention ethics, ethicality or moral capabilities at all. There is only a single entry within the document which states that teachers should "demonstrate and model the positive values, attitudes and behaviours expected of children" (ibid, 2), and the more ambiguous commitment to "make a positive contribution to the wider life and ethos of the setting" (ibid, 5). With singular uses of terminology such as sensitivity, safety and care it would seem the standards support the notion of innate moral ethicality with implicitly ethical commitments, however, these connections are vague and tenuous rather than sharply defined. Within the Quality Assurance Agency (QAA) (2019) benchmarks; (these govern the knowledge and skills required for bachelor and master degrees in childhood studies in the UK), to "reflect upon the ethics of studying babies and young children and their families and communities" (ibid, 10) is included. However there is no guidance on whose vision of ethics should be promoted, therefore there is no ethical depth; detail and expansiveness is by no means guaranteed. This raises the question of how HE educators might support students in developing the necessary knowledge, skills and capacities to navigate the ethical messiness that can be experienced within day-to-day practice. Without defined parameters it is easy to see how students and newly qualified educators could 'arrive' in their settings ethically ill-equipped and ill-prepared for the realty of EYE.

However, the issue is not that practitioners do not strive to be ethical or endeavour to maintain their ethicality within practice. For example within the UK EY practitioners adhere to their own code of ethics (Early Education 2011), Denmark has recently established an early years ethical code (Lauth and Sorensen 2013 cited in Ribers, 2018, 894), as have America (Ambery et al., 2011) and Australia (Barblett et al., 2006), and there is an international code of ethics created by Whitehead and Aviles (2018). Although the increased attention to ethics within these codes of practice it largely welcomed, as Niesche and Haase $(2012,278)$ argue, ethics is more than just complying with a list of capabilities, capacities and commitments, an ethical approach should not serve to narrow and reduce practice, but to develop transformative reflective and reflexive skills.

If ethics underpins and permeates life and professional practice, much like the horizontal growth of the rhizomatic bamboo grass (Uzelman, 2005), then as Ribers (2018) suggests it should be a cornerstone of teacher training and practice preparation. Malone (2020) infers that relying on inherent and implicit commitments and espoused ethical principles presupposes that every practitioner is willing and capable of being reflective and reflexive about their practice, their relationships and their impact on a day-to-day basis. This is not always the case, and Dewey $(1910,12)$ describes a need for some to "overcome inertia that inclines one to accept things at face value". As the quote which opens this section suggests, how can we, as practitioners and educators, fully appreciate the ocean of ethical expectations that we have been swimming in, without being occasionally pulled from the comfort of the water to view the ever-stirring vastness? 
This level of deep reflection and reflexivity is encompassed within the honest accounts of two ethical educator journeys detailed within Niesche and Haase (2012). These everyday micro-ethical accounts demonstrate that embodied ethicality is far more complex and demanding than compliance with legislation (Moss, 2019, 57), which merely leads to the "ethical becoming the technical" (Dahlberg and Moss, 2005, 70). In order to construct ourselves as ethical beings and ethical professionals, Niesche and Haase $(2012,276)$ argue that self and professional reflection is vital; it is a deeply emotional and cultural ongoing lifelong dynamic, requiring meaningful commitment. Through a Foucauldian lens (1983, 1984) transformative ethical practice subjects practitioners to constant self-reflection in relation to actions and relational encounters, almost akin to an ethical self-actualization. In this sense a practitioner's personal and professional ethical identity is constantly evolving and renegotiated. Butler $(2005,37)$ explains how this aligns with "self-reflection and sociocultural recognition", the way ethical identity impacts on and is impacted by social discourses and cultural conventions.

To this end, teacher training and practice preparation programmes should support EY practitioners in developing their own ethical and professional integrity. This would foster ethical resilience and inform practitioner's reflective and reflexive practices. Students should be encouraged to explore ethics in a deeper way, honouring its multifaceted nature and becoming inspired to challenge traditional ethical epistemologies and fixed ethical and moral positions emerging from political positions of power. In this way students would have the opportunity to fully realise their ethical identities and evolve into EY practitioners that were fully prepared and equipped to shoulder the mantle of Other, enabling the children that they nurture to do the same.

It is not surprising that EYE, within the current neoliberal socioeconomic climate and increasingly standardised practices and discourses, is beset with multiple, unpredictable and complex realities, where ethical dilemmas often emerge. It is within this daily reality that ethical ideals and complex and/or shades-of-grey dilemmas converge, which places increased ethical pressures on practitioners. This is to say nothing of the potential impacts of others' views and expectations; parents and colleagues for example, on practitioner's ethicality, practice and professional conduct. Within this reality, ethical ideals or espoused theory is often thwarted by rigid policy or parent and colleague expectations, resulting in a more uncomfortable compromise or theory-in-action (Schon, 2016). There are issues of asymmetrical power relationships, silence and privilege, which many practitioners may be underprepared to grapple with (Malone, 2020). It has been well documented within early years practice that ethical dilemmas often fall outside of the narrow parameters supported by universal ethical perspective and principles (Malone, 2020; Ribers, 2018). Despite ethical codes of practice and regulatory guidelines, Grahams (2015), Riber (2018) and Malone (2020) all contest that many practitioners feel ill-equipped and isolated when navigating more complex ethical challenges and dilemmas.

The unpredictable and undulating ethical terrain can leave practitioners relying on "their own ethical principles, previous experiences and institutional ethics requirements" (Grahams, 2015,2 ), which may or may not be sufficiently helpful. Within this trying professional context Ribers $(2018,902)$ discusses the emergence of 'moral distress'. This is a value-laden tension which emerges within practice when a practitioners personal and professional ethical ideals, the complex realities and socioeconomic pressures inherent in EYE and ethical codes and regulatory practices cannot be reconciled (Malone, 2020; Niesche and Haase, 2012; Ribers, 2018). The ensuing feelings of stress, inadequacy and subsequent potential for burnout, is reminiscent of the negative impacts to practitioner well-being identified within Taggart (2011) and Elfer's $(2012,2015)$ notions of emotional labour. Therefore, 
better preparing practitioners for the ethical demands of their practice is more a necessity than an ideal. Whilst Niesche and Haase (2012) encapsulate how powerful ethically reflective and reflexive practice can be with regard to professionalism, ethical identity and ethical being; moral distress can have an equally potent reverse impact. Potentially it places "professional integrity and self-esteem" and practitioner well-being at risk (Ribers, 2018, p.896). Practitioners need a way of re-imagining ethics in its entirety and its complexity, to accommodate all pathways and embrace their own ethical understanding of values. Only then can they effectively challenge discursive practice with confidence, to readdress any issues relating to social justice and equitable practice as identified by Ribers (2018) and Malone (2020).

Foucault $(1983,1984)$ proposes that ethics is an expansive process where moral and ethical states of being can be enacted as a way of transforming self and practice, an enactment of freedom and emancipation. This is not necessarily a process that can be contained within normative and technicist EY discourses and statutory legislation, and often requires a circumventing of disciplinary power (Foucault, 1983, 1984; Malone, 2020; Niesche and Haase, 2012; Ribers, 2018). It challenges practitioners, when faced with ethical dilemmas and challenging situations, to "have the courage to say no... and dissent when actions violate professional ethical guidelines" or individual ethical positionality (Ribers, 2018, 897). This "plight to dissent" for the EY practitioner is not just a "voluntary right but a professional obligation" (ibid). A notion that echoes the principles of both an ethics of care (Noddings, 2015; Tronto, 2013) and ethics of encounter (Levinas 1989 cited in Dahlberg \& Moss, 2005, 76-81), through shouldering the burden of Other, acting as both advocate and protector. However, as Malone (2020) highlights, the issues of professional vulnerability and power endemic within this endeavour can become an added complication and the potential for moral distress increased. Challenging the status quo requires a willingness to embrace uncertainty, to put at risk the sense of safety that can result from conformity and Sameness. It takes courage to resist and problematize existing power dynamics and discursive discourses.

Rhizomatic approaches could offer a conceptual way for EY practitioners to accommodate multiple ethical principles and paradigms, within the complicity of daily reality within EYE (Deleuze and Guattari, 1987). As a metaphorical structure rhizomatic approaches could allow practitioners to adopt more ethically nomadic positions, their thoughts and reflections flowing freely through ethical dilemmas and challenges, encompassing multiplicity and many ethical and moral pathways, rather than becoming mired in fixed and binary positions. This flexibly has the potential to mitigate instances of Ribers' (2018) moral distress and the impacts of a plight of dissent, and foster professional integrity, self-esteem and ethical resilience. Borrowing from Krejsler (2016, 1482), practitioners need to become "competence nomads...conceptual personas...that scan innate forces and conceptual landscapes in constructively rebellious ways". The competent nomad accomplishes this while remaining true to their own personal and professional ethical stance, in a professional field that is constantly changing and unpredictable, as is the nature of working with very young children. Employing a Deleuzo-Guattarian (1987) rhizomatic approach practitioners are challenged to ask of every ethical encounter: what else exists here? How does it work? 'and...and...and', to fully engage with what is produced through the movements and entanglements of the often disparate elements within relational encounters. A rhizomatic approach to ethics incorporates ethical multiplicity and the potential for opening-up to evermore expanding ethical possibilities, leading to potentially uncharted ethical territories, whilst simultaneously offering practitioners opportunities to 'ethically be' within practice: to recognise and cultivate their own ethical ocean in which to become drenched. 
In that way practitioners can develop and reconcile an ethical consciousness within EYE in relation to the subjective relational context within which they work (Ribers, 2018, 897).

\section{Ethical Mechanisms and Asymmetrical Power Relations Within EYE Provision}

"In every respect, the war machine is of another species, another nature, another origin than the state apparatus"

Deleuze and Guattari $(1987,411)$.

Ethical values can be subjective to the individual and appropriated by those in positions of power. In practice it can be hard to define where the ethical boundaries between macro and micro terrains begin and end. This can leave practitioners' in a place where they are either unaware of the affects of governmentality on their ethical practices, or in a positon of needing to reconcile personal ethical values alongside a hegemonically sanctioned ethical practitioner identity. A further exploration of the political aspects surrounding ethics and EYE provision, allows practice tensions to emerge and the potential discursive professional impacts to be analysed in greater depth and detail.

Barad $(2007,396)$ argues that our ethical values course not just through all our relational encounters but through the very "marrow of being". However, as previously discussed, it is not always clear whose version of ethicality and what dimension of ethics should be engaged with. Ethics weaves between macro and micro terrains depending on the focus that is ascribed (Gallagher, 2009). But whilst EY practitioners may not be entirely comfortable with the notion, EYE is, as Dahlberg and Moss (2005) and Moss (2019) suggest, a site of both political and ethical practice. A practitioner's ethicality functions like the grassroots of the rhizomatic bamboo (Uzelman, 2005, 17): simultaneously grounding, and acting upon and acting within and affecting and causing effect upon a practitioner's ethical identity (professional and personal) as well as their behaviour and conduct (professional and personal). Essentially, practitioners' 'ethically being' within EYE consciously and unconsciously effects and affects EYE. Barad (2007, 384) describes it aptly when stating "ethics is about mattering, about taking account of the entangled materializations of which we are a part".

Yet, as previously discussed, through a Foucauldian (1983) lens ethicality, just like any other dominant discourse, can become a regime, a way to simultaneously function as a powerful, sovereign and disciplinary mechanism. In this vision of ethics it is always a form of governmentality, the affects and effects of the 'system', society and culture which operate on and through educators, legislation and, increasingly, standardised and regulated provision, normative and technicist discourses and standardised practices (Butler, 2005, 2015; Dahlberg and Moss, 2005; Davies, 2018; Foucault, 1983, 1984; Moss, 2019). Therefore, it can be beneficial to explore what ethical mechanisms are employed by the system (the state) as disciplinary mechanisms, and how metaphorical concepts such competence nomad and rhizome can be employed to resist and challenge face-value, taken-for-granted and one-size-fits-all dominant discourse. As Barad (2007, 3) observes, even the "smallest parts of matter are found to be capable of exploding deeply entrenched ideas and large cities".

From a macro-ethical perspective it could be argued that there is some contention about whether disciplinary mechanisms begin within the ethico-political arena or within the realms of ontology and epistemology; the "ethico-onto-epistemological" space where ontology, 
epistemology and ethics coexist (Bazzul, 2018, 477). An ethico-onto-epistemological stance would seek to (re)conceive ethics, considering notions that challenge multiplicitous ways of being ethical, multiple ethical responses and multiple ethical beings and becomings (Bazzul 2018, 477). Furthermore, this would resist Cartesian-based arguments (Shockey, 2010), where ethical codes are grounded in good/common sense and simplistic, binary and dualistic ethics rooted in right/wrong and good/bad or even good/evil (Bauman, 1995). Although, it could be argued that it is within these more dichotomous and binary arguments that the drive for unification emerges and the ethico-politcal influence interweaves with EYE. It seems rather ironic that governmentality ascribes the 'correct' and universal sociocultural meaning to binary stances reflecting Cartesian logic. Yet, according to Cowell, Downe and Morgan (2013) the abuses of asymmetrical power relationships and disciplinary power to silence and privilege conduct are enacted within the political sphere as they are on society and professional practice. Crowell et al. (2013 p.30) argue that "governments regularly struggle to define good conduct", yet they employ ethical mechanisms; in the form of legislation and regulations, to establish and enforce ethically "good conduct" and regulate behaviours. Consequently, by the nature of this practice, relationships of power which further produce technologies of governance and the self, emerge.

Interestingly, although Cowell, Downe and Morgan's (2013) discussions centred on the impacts of politicians' resistance to ethicality, their findings are just as applicable to EYE as public office. Governmentality expressed within EY policy and legislation governs "the ocean" we as practitioners, parents/carers and the children in our care, "are drenched in" (Gilligan, 2011, 15-16). Whilst practitioners' may or may not be aware of this ocean, it functions as a conscious and unconscious hegemonic sanctioning of a practitioner's ethical identity (both professional and personal), which further impacts upon their behaviour, conduct and practice. Essentially, is serves to provide an officially sanctioned image of ethics, with an effectively written view on what ethicality should entail for compliant practitioners. Ethics matters and practitioners matter in resisting discursive ethical discourses and problematising the resulting asymmetrical power relations that can emerge. As identified in Cowell, Downe and Morgan (2013) the impacts of these power relations and disciplinary and sanctioning mechanisms that allow these to flourish, cannot be underestimated, nor the impacts they may have on the conduct of self and others, in both empowering and disempowering ways. As previously stated, practitioners' approach to ethical dilemmas and the choices they make either serve to challenge silenced voices and privileged dominant discursive discourses, or they intentionally or unintentionally reinforce them as regimesof-truth (Foucault, 1983, 1984). Bazzul $(2018,468)$ refers to this challenging as the need for "ethico-political action" as a way to grapple with discursive practice, "destructive hierarchies" and issues of social and interspecies justice. It is often the resulting quagmire of ethical regimes; sovereign and disciplinary mechanisms and asymmetrical power relations that are least anticipated by practitioners within EYE and, for which, they are least prepared. It is with this in mind that Dahlberg and Moss (2005) and Moss (2019) argue it is vital practitioners acknowledge the political and ethical nature of EYE, it is, after all, the practitioners own ethicality that can potentially (de/re)territorialize ethical practice.

Crowell et al. $(2013,30)$ argue that ethical regulations often codify and simplify ethical principles to ensure universal applicability. Although many argue that a unified ethical practice code within EYE does not really exist (Barblett et al. 2006; Early Education 2011; Ambery, et al. 2011; Lauth and Sorensen 2013 cited in Ribers, 2018, 894), despite an international code emerging from Whitehead and Aviles (2018), cultural ethical codes are in force governing practice in EYE. For example, Malone (2020, 81), suggests that ethical codes such as those produced by the British Educational Research 
Association (2018) presuppose a priori acknowledgement and acceptance for ethical responsibility. This reduces ethics to mere tick box codes of 'doing ethics', impoverishes understanding and renounces a practitioner's individual responsibility for sound moral and ethical ways of being. From the perspective of Other and ethics of care, (Noddings, 2015; Tronto, 2013), an acceptance and repersonalisation of ethics would embrace Otherness and provide a foundational ethicality enacted by practitioners before engaging with ethical codes. However, as previously discussed, without proper training and preparation for ethical endeavours that are inherent in EYE (Barron, 2016; Dahlberg and Moss, 2005; Malone, 2020; Ribers, 2018; Taggart, 2011) practitioners are often without this a priori ethical underpinning and therefore struggle to assume responsibility for Other, potentially allowing moral distress and ethical disillusionment to ensue.

Whilst it is not reasonable to suggest that life of any sort should function without the ability to make ethical judgements, ostensibly, Powell, (2012, 45) claim that "ethical codes are only ever starting points", they represent regulatory and statutory rules and rights that embody the sanctioning and disciplinary power machines. However, within EYE there will, as previously stated always be ambiguities and complexities of reality inherent within practice that often fall outside of the narrow parameters represented in codes and legal conventions. Dahlberg and Moss $(2005,68)$ argue that educators are not supported in repersonalising ethics, and, this can have damaging impacts to practitioner's well-being and professional confidence (Barron, 2016; Ribers, 2018; Malone, 2020). Practitioners are expected to conform to ethical codes and guidelines without question. Dahlberg and Moss $(2005,68)$ argue that "Responsibility is exchanged for legislation, the need to choose for rule-following, ambivalence for certainty". Yet they often feel ill-equipped, isolated and unsupported in navigating ethical realities, therefore the question remains, whether ethicality should be about integrity, compliance or both.

Moss $(2019,59)$ suggests that ethicality and active ethical practices, first and foremost, should support responsibilities and relationships, rather than just contending with rights, rules and principles to be followed. Bolt (2018 p.67) advocates that there is active relational quality to ethics that cannot and should not be ignored; that ethics is always about hearing a "call that demands a response". When an ethical invitation is accepted, it then requires a relational response as an answer and this will entail making informed ethical choices rather than adhering to blind compliance. It will require practitioners to be capable of thinking of themselves in relationship with Other, whether that is a parent/carer, child, colleague or something more (Moss, 2019, 56). As St Pierre $(2000,25)$ once observed "the call for ethical practice shifts from grand, sweeping statements about truth and justice to engagements with specific, complex problems that do not have generalizable solutions".

Bauman $(2000,1)$ suggests "we share the world, and so we willy-nilly affect each other's lives; what we do or abstain from doing is not indifferent to the life of others". By assuming the mantle of responsibility for relationships we are already ethical beings, "existence is not an individual affair" (Barad, 2007, ix). In order to problematize hegemonic ethical perspectives, systems need to be made visible (Davies, 2018) and this is not achieved via checklists and protocols. As Bauman $(2000,2)$ suggests ethics and morality need to be akin to midwives rebirthing practitioners relational encounters, the way they express their ethical identity (both professional and personal) their behaviour, conduct and practice. Ethics is a call and practitioners are invited to respond; but how, and in what way, remain personal choice. 


\section{Conclusion or is This a Beginning?}

“There is always more to think” (May, 2005, 21).

The purpose of this article was to offer some further thoughts to the academic debate surrounding the nebulous field of ethics with a particular focus upon the EYE practitioner as a conduit of ethical principles. It has not sought to subject ethics to a neat unification or made any claims to 'truth' as this would contravene the very positionality of the debate. However, hopefully it has shown, as Bazzul $(2018,474)$ observed, that "there is literally an infinite number of ways of living and being ethical". By employing Deleuzo-Guattarian (1987) concepts such as the rhizome and the competence nomad (Krejsler, 2016), the multiple and often divergent facets of ethics can be embodied. Thus a fuller and richer picture of ethics can be (re)conceptualised by resisting normative and hegemonic amalgamations and (re)imagining ethics, engaging with different ethical possibilities. Engaging with this process provides the EY practitioner with opportunities to reconcile and develop their own ethical consciousness within EYE (Ribers, 2018, 897).

A rhizomatic and Deleuzo-Guattarian (1987) philosophical approach to ethics demands that practitioners stop, and pay attention to, the multiplicity and complexity around them; to see things differently and to uncover layers of meaning and connection that may not have been seen before. Essentially, it is practitioners own ethicality that can potentially (de/re) territorialize ethical practice within their classrooms and settings, their approach to ethical responsibilities and their ethical choices that determine socially just and equitable EY provision for all. If practitioners were to stop and ask what else exists here? How does it work? What is the ethically right thing to do here? 'and...and...and', if practitioners worked the ethical rhizome, then they open the door to the potential for the children that they work with to develop ethical freedom to deliberate their own ethical possibilities.

As tutors within further education with the responsibility of training our future educators, it is essential that we too (re)conceptualise our understanding of ethics. Ensuring that ethics occupies a more prominent position within training and graduate and post-graduate programmes of study, will provide a stronger ethical foundation for EY practitioners and ensure they are better equipped for the complexities of daily reality within EYE. Solvason (2016, 45-46) articulates this well when stating "ethics is not something to be taught but embraced...", further claiming that in creating space for ethics to be freely explored in training programmes affords it the same importance as any other professional skill. It is not about moving away from merely considering procedural protocols and guidelines; it is about discussing these alongside the wider facets of ethics, to travel the multiple pathways that emerge within deeper ethical debates and experiences.

We live in a world where we are constantly encouraged to think about one right pathway, one right view about something and yet this is merely an illusion; there are many pathways to sense and meaning, many pathways to knowledge and understanding. Unless, as educators, we "aspire to extend the discourse on ethicality...rather than accepting these matters implicitly, as we often do, assuming a shared understanding between student and tutor" (Solvason, 2016, 45), ethics may remain impoverished with EYE. We need to support our future educators in embracing ethical multiplicity; to scaffold ways in which they can develop their criticality and diversity of thinking, so that they develop the ability to enact their ethical freedom by forming their own ethical judgements within the moment. We have a responsibility to ensure that we encourage our future educators to open the door to their own ethicality, so that they may in turn open-up possibilities and potentials with 
the children they work with, to engage differently so that the divergent facets of ethics can be embodied in new and diverse ways.

Author contributions All authors contributed to the study conception and design. All authors read and approved the final manuscript.

Funding The authors did not receive support from any organization for the submitted work. No funding was received to assist with the preparation of this manuscript. No funding was received for conducting this study. No funds, grants, or other support was received.

Finance The authors have no relevant financial or non-financial interests to disclose. The authors have no conflicts of interest to declare that are relevant to the content of this article. All authors certify that they have no affiliations with or involvement in any organization or entity with any financial interest or non-financial interest in the subject matter or materials discussed in this manuscript. The authors have no financial or proprietary interests in any material discussed in this article.

Open Access This article is licensed under a Creative Commons Attribution 4.0 International License, which permits use, sharing, adaptation, distribution and reproduction in any medium or format, as long as you give appropriate credit to the original author(s) and the source, provide a link to the Creative Commons licence, and indicate if changes were made. The images or other third party material in this article are included in the article's Creative Commons licence, unless indicated otherwise in a credit line to the material. If material is not included in the article's Creative Commons licence and your intended use is not permitted by statutory regulation or exceeds the permitted use, you will need to obtain permission directly from the copyright holder. To view a copy of this licence, visit http://creativecommons.org/licenses/by/4.0/.

\section{References}

Ambery, M., et al. (2011). NAEYC code of ethical conduct and statement of commitment. https://www.naeyc. $\mathrm{org} /$ sites/default/files/globally-shared/downloads/PDFs/resources/position-statements/Ethics\% 20Position\%20Statement2011_09202013update.pdf

Aubrey, et al. (2000). Early childhood educational research: issues in methodology and ethics. London: Routledge.

Banks, S., \& Gallagher, A. (2008). Ethics in Professional Life: Virtues for Health and Social Care. Red Globe Press.

Barad, K. (2007). Meeting the Universe Halfway: Quantum Physics and the Entanglement of Matter and Meaning. Duke University Press.

Barblett, et al. (2006). Childhood Australia code of ethics http://www.earlychildhoodaustralia.org.au/ourpublications/eca-code-ethics/

Barron, I. (2016). Flight turbulence: the stormy professional trajectory of trainee early years' teachers in England. International Journal of Early Years Education, 24(3), 325-341.

Bauman, Z. (1995). Life in fragments, essays in postmodern reality. Blackwell Publishers.

Bauman, Z. (2000). Ethics of individuals. Canadian Journal of Sociology, 25(1), 1-11.

Bazzul, J. (2018). Ethics, subjectivity, and sociomaterial assemblages: two important directions and methodological tensions. Studies in Philosophy and Education, 37, 467-480.

Bolt, B. (2018). Couch grass: ethics of the rhizome. In C. Asberg \& R. Braidotti (Eds.), A feminist companion to the posthumanities (pp. 67-80). Springer.

British Educational Research Association (BERA). (2018). Ethical Guidelines. https://www.bera.ac.uk/ researchers-resources/publications/ethical-guidelines-for-educational-research-2018

Butler, J. (2015). Senses of the subject. Fordham University Press.

Butler, J. P. (2005). Giving an account of oneself (1st ed.). Fordham University Press.

Crowell, R., Downe, J., \& Morgan, K. (2013). Managing politics? ethics regulation and conflicting conceptions of "good conduct." Public Administration Review, 74(1), 29-38.

Dahlberg, G., \& Moss, P. (2005). Ethics and politics in early childhood education. RoutledgeFalmer. 
Davies, B. (2018). Ethics and the new materialism: a brief genealogy of the 'post' philosophies in the social sciences. Discourse: Studies in the Cultural Politics of Education, 39(1), 113-127.

Deleuze, G. \& Guattari, F. (1987). reprinted 2013. A thousand plateaus. London: Bloomsbury.

Dewey, J. (1910). reprinted 2015. How we think. Kindle addition: Some good Press.

Education, E. (2011). Code of ethics. Early Education.

Edwards, et al. (2011). The hundred languages of children: the Reggio Emilia experience in transformation (3rd ed.). ABC-CLIO.

Elfer, P. (2012). Emotion in nursery work: work discussion as a model of critical professional reflection. Early Years, 32(2), 129-141.

Elfer, P. (2015). Emotional aspects of nursery policy and practice -progress and prospect. European Early Childhood Education Research Journal, 23(4), 497-511.

Erickson, S., Hoglund, A. T., \& Helgesson, G. (2008). Do Ethical Guidelines Give Guidance? A Critical Examination of Eight Ethics Regulations. Cambridge Quarterly of Healthcare Ethics, 17(1), 15-29.

Fisher, B. \& Tronto, J. (1990). Towards a feminist theory of caring. In Abel, E. K. \& Nelson, M. K. (Eds.). Circles of care work and identity in women's lives (pp. 35-62). New York: University Press.

Foucault, M. (1983). On the genealogy of ethics: an overview of work in progress. In Rabinow, P. (Ed.). Ethics, subjectivity and truth: the essential works of Foucault 1954-1984 (vol. 1., pp. 253-280). London: Penguin Books.

Foucault, M. (1984). The ethics of the concern of self as a practice of freedom. In Rabinow, P. (Ed.). Ethics, subjectivity and truth: the essential works of Foucault 1954-1984 (vol. 1., pp. 281-301). London: Penguin Books.

Freire, P. (1994). reprinted 2014. Pedagogy of Hope: Reliving Pedagogy of the oppressed. London: Bloomsbury Revelations.

Gallagher, M. (2009). Ethics. In K. Tisdall, J. Davis, \& M. Gallagher (Eds.), Researching with children and young people: Research design, method and analysis (pp. 11-57). Sage Publications.

Gilligan, C. (2011). Joining the resistance. Polity Press.

Graham, A. (2015). Ethical research involving children: putting the evidence into practice. Family Matters : Newsletter of the Australian Institute of Family Studies, 96, 22-28.

Kose, B. W. (2011). Developing a Transformative School Vision: Lessons From Peer-Nominated Principals. Education and Urban Society, 43(2), 119-136.

Krejsler, J. B. (2016). Seize the opportunity to think differently! A Deleuzian approach to unleashing becomings in education. Educational Philosophy and Theory, 48(14), 1475-1485.

Malone, D. M. (2020). Ethics education in teacher preparation: a case for stakeholder responsibility. Ethics and Education, 15(1), 77-97.

May, T. (2005). Gilles Deleuze an introduction. Cambridge University Press.

Moss, P. (2019). Alternative narratives in early childhood. Routledge.

National College for Teaching and Leadership (NCTL). (2013). Teaching standards (early years). Department for Education (DFE). https://www.gov.uk/government/uploads/system/uploads/attachment_data/ file/211646/Early_Years_Teachers__Standards.pdf

Niesche, R., \& Haase, M. (2012). Emotions and ethics: a Foucauldian framework for becoming an ethical educator. Educational Philosophy and Theory, 44(3), 276-288.

Noddings, N. (2015). Care ethics and caring organisations. In D. Engster \& M. Hamington (Eds.), Care ethics and political theory (pp. 72-84). University Press.

Powell, et al. (2012). International literature review: ethical issues in undertaking research with children and young people. Childwatch International Research Network.

Punch, M. (1994) 'Politics and ethics in qualitative research', in Denzin, N.K. and Lincoln, Y.S. (eds.) Handbook of qualitative research. London: Sage, pp. $83-95$.

QAA. (2019). Subject benchmark statement early childhood studies. QAA.

Ribers, B. (2018). The plight to dissent: professional integrity and ethical perception in the institutional care work of early childhood educators. European Early Childhood Education Research Journal, 26(6), 893-908.

Schön, D. A. (2016). The reflective practitioner: how professionals think in action. Routledge.

Shockey, R. M. (2010). Heidegger's Descartes and Heidegger's Cartesianism. European Journal of Philosophy, 20(2), 285-331.

Solvason C. (2016). Ethicality, research and emotional impoverishment in a technological era. In McNiff, J. (Eds). Values and Virtues in Higher Education Research (pp. 33-47). London: Routledge.

Pierre, St. (2000). The Call for Intelligibility in Postmodern Educational Research. Educational Researcher, 29(5), 25-28. 
Taggart, G. (2011). Don't we care? The ethics and emotion labour of early years professionalism. Early Years International Research Journal, 31(1), 85-95.

Tronto, J. C. (2013). caring democracy markets equality, and justice. University Press.

Uzelman, S. (2005). Hard at work in the bamboo garden: Media activists and social movements. In A. Langlois \& F. Dubois (Eds.), Autonomous media: Activating resistance and dissent (pp. 17-27). Cumulus Press.

Whitehead, D., \& Aviles, J. M. (2018). International code of ethics for educators. Childhood Education International.

Publisher's Note Springer Nature remains neutral with regard to jurisdictional claims in published maps and institutional affiliations. 